\title{
Continental-scale variability in browser diversity is a major driver of diversity patterns in acacias across Africa
}

\author{
Michelle Greve $^{1 *}$, Anne M. Lykke ${ }^{2}$, Christopher W. Fagg ${ }^{3}$, Jan Bogaert ${ }^{4}$, Ib Friis ${ }^{5}$, \\ Rob Marchant ${ }^{6}$, Andrew R. Marshall ${ }^{6,7}$, Joël Ndayishimiye ${ }^{8}$, Brody S. Sandel ${ }^{1,9}$, \\ Christopher Sandom ${ }^{1}$, Marco Schmidt ${ }^{10,11}$, Jonathan R. Timberlake ${ }^{12}$, Jan J. Wieringa ${ }^{13}$, \\ Georg Zizka $^{10,11}$ and Jens-Christian Svenning ${ }^{1}$
}

${ }^{1}$ Ecoinformatics \& Biodiversity Group, Department of Bioscience, Aarhus University, Ny Munkegade 114, DK-8000 Aarhus C, Denmark; ${ }^{2}$ Terrestrial Ecology, Department of Bioscience, Aarhus University, Vejlsøvej 25, DK-8600 Silkeborg, Denmark; ${ }^{3}$ Herbário UB e Faculdade de Ceilândia, Instituto de Ciências Biológicas bloco 9, 10 piso, Universidade de Brasília - Campus Darcy Ribeiro Asa Norte - Brasilia-DF - 70910-900, Brazil; ${ }^{4}$ Gembloux Agro-Bio Tech, Unité Biodiversité et Paysage, Université de Liège, Passage des Déportés, 2 B-5030 Gembloux, Belgium; ${ }^{5}$ Natural History Museum of Denmark, University of Copenhagen, Gothersgade 130, 1123 København K, Denmark; ${ }^{6}$ York Institute of Tropical Ecosystem Dynamics and Centre for Integration of Research, Conservation and Learning (CIRCLE), Environment Department, University of York, York Y010 5DD, UK; ${ }^{7}$ Flamingo Land Ltd., Kirby Misperton, North Yorkshire Y017 6UX, UK; ${ }^{8}$ Service d'Ecologie du Paysage et Systèmes de Production Végétale, Université Libre de Bruxelles, 50 Avenue F.D. Roosevelt, CP 169, B-1050 Bruxelles, Belgium; ${ }^{9}$ Center for Massive Data Algorithmics (MADALGO), Department of Computer Science, Aarhus University, Aabogade 34, DK-8200 Aarhus N, Denmark; ${ }^{10}$ Institute for Ecology, Evolution and Diversity, Goethe University, Siesmayerstr. 70, 60323 Frankfurt, Germany; ${ }^{11}$ Biodiversity and Climate Research Centre (BiK-F) and Department of Botany and Molecular Evolution, Research Institute Senckenberg, Senckenberganlage 25, 60325 Frankfurt, Germany; ${ }^{12}$ Herbarium, Library, Art and Archives, Royal Botanic Gardens, Kew, Richmond, Surrey, TW9 3AB, UK; and ${ }^{13}$ Netherlands Centre for Biodiversity Naturalis (section NHN), Herbarium Vadense, Biosystematics Group, Wageningen University, General Foulkesweg 37, 6703 BL Wageningen, The Netherlands

\section{Summary}

1. It has been proposed that, across broad spatial scales, climatic factors are the main drivers of ecological patterns, while biotic factors are mainly important at local spatial scales. However, few tests of the effect of biotic interactions on broad-scale patterns have been conducted; conclusions about the scale-dependence of the importance of biotic interactions thus seem premature.

2. We developed an extensive database of locality records of one of Africa's most conspicuous groups, the acacias (the genera Senegalia and Vachellia), and used species distribution models (SDMs) to estimate the distribution of all African acacias.

3. African acacias are particularly well adapted against mammalian herbivory; therefore, we hypothesized that browser diversity could be an important driver of acacia richness. Species richness maps for the two genera were created from SDM-generated maps. Ordinary least square (OLS) regressions and, to consider spatial autocorrelation, simultaneous autoregressive (SAR) analyses were used to model richness of the two genera in relation to mammalian browser richness, current environment (including climate), and climate history since the Last Glacial Maximum (LGM). We used variation partitioning to determine what percentage of variation could be explained by these three groups of factors.

4. Both genera showed centres of richness in East Africa and the Limpopo Basin of southern Africa. Browser richness was the best explanatory variable for richness of both genera. Environmental factors explained negligible variation in the richness of Senegalia, but some variation in Vachellia. For both genera, the residuals of the species richness model of one genus also explained 
much variation in the richness of the other genus, indicating that common factors not considered in the richness analyses here may additionally be driving the richness of both genera.

5. Mechanisms that could generate a correlation between browser and acacia richness are proposed, and differences in the determinants of richness patterns of Senegalia and Vachellia discussed in the light of the two genera's history of colonization of Africa.

6. Synthesis. This is the first study that demonstrates that consumer diversity can influence richness patterns at continental scales and demonstrates that biotic factors can drive richness even at broad spatial scales.

Key-words: diversity patterns, herbivory, plant-herbivore interactions, Quaternary climate change, resource-consumer relationships, savanna species, speciation

\section{Introduction}

Broad-scale species richness patterns and their drivers have long fascinated scientists (Hawkins et al. 2003; Willig, Kaufman \& Stevens 2003; Hawkins, Rodríguez \& Weller 2011). A meta-analysis of the drivers that underlie such richness patterns has shown that water, energy or water-energy variables are often the best explanatory factors of species richness in both plant and animal taxa (Hawkins et al. 2003). Other evolutionary and environmental factors such as historical biogeography, palaeoclimate, environmental heterogeneity and edaphics have sometimes also been shown to be of importance, although usually less so, for richness patterns (see Field et al. 2009). How biotic interactions affect richness patterns is less well explored.

It has been suggested that, while climate is a major determinant of ecological patterns at broad scales, biotic interactions are of little importance at these scales (McGill 2010). However, others have argued that biotic interactions can play a more important role in macroecological processes than is widely thought, for example, as determinants of species distributions (Araújo \& Luoto 2007). In species richness analyses, it has been shown that resource richness can successfully explain consumer richness patterns at broad spatial extent, including across continents (e.g. Kissling, Rahbek \& Böhning-Gaese 2007; Qian et al. 2009; though see Jetz et al. 2009). However, whether consumers affect richness patterns of resource species has not previously been tested at continental scale, despite the well-known strong effects of consumers on local community structure and dynamics (Cumming 1982; du Toit \& Cumming 1999).

We examine which factors determine species richness patterns of acacias, a group of mimosoid trees and shrubs (and more rarely lianas) that dominates much of the vegetation of the arid savannas of Africa (Huntley 1982), and can be locally common in other habitats from semi-desert conditions to montane forests. In Africa, acacias are represented by two genera, Senegalia Raf. and Vachellia Wight \& Arn. While the first mimosoids were forest species, the ancestor of Vachellia originated in more arid open habitats in the early Miocene and experienced one colonization event into Africa, where it mainly diversified in open habitats (Bouchenak-Khelladi et al. 2010). In contrast, Senegalia originated in the closed forests of South America, and its presence in Africa can be attributed to at least two cross-continental dispersal events in the late Miocene (Bouchenak-Khelladi et al. 2010). One of the resulting clades became adapted to and diversified in open habitats, while the other, smaller, clade remained in closed habitats. Therefore, although both genera possess some forest species, the majority of species are found in the more open habitats of African savannas (Bouchenak-Khelladi et al. 2010).

It is well-established that herbivores have a substantial effect on vegetation structure and plant species composition (Hester et al. 2002), particularly in African savannas, where large mammalian herbivores (particularly ungulates) persist, or have until very recently persisted, across vast areas. Here they are thought to act as ecosystem engineers and to have influenced the evolution and distribution of the savanna vegetation (Cumming 1982; Scholes \& Walker 1993; du Toit \& Cumming 1999). Various studies have also shown that plant species richness is affected by herbivore diversity (see Hester et al. 2002), although such tests have usually been conducted at local scales. Given the ubiquity of acacias in drier savannas across the African continent, they constitute an appropriate group to test whether biotic interactions, in the form of herbivory by browsers, affect plant diversity patterns. Acacia browse is favoured by many large herbivores (Timberlake, Fagg \& Barnes 1999), and the variety of defence and tolerance traits that acacias have developed to deal with the impact of browsing (Ross 1979; Scholes \& Walker 1993) indicates that the group has been evolving under strong selection by mammalian herbivores. Amongst these traits are thorns (spinescent stipules in Vachellia and prickles in Senegalia), which slow the browsing rate (Cooper \& Owen-Smith 1986); chemical defences, which reduce leaf palatability (Cooper \& Owen-Smith 1985); ant-acacia symbioses, where ants obtain housing and nectar from trees, and trees obtain herbivore protection in return (Palmer et al. 2008); and phenotypic plasticity of traits such as increasing thorn size (Milewski \& Madden 2006) and spacing (Fornara $\& \mathrm{du}$ Toit 2007), and increasing branch growth rates and denser branching patterns (Fornara \& du Toit 2007), which also reduce browsing rates. Therefore, we predict that browser richness may affect acacia richness.

In addition to large herbivores, richness patterns of acacias are likely to be influenced by factors that are recognized as richness drivers for broader groups of organisms such as trees in general, namely current climate and habitat heterogeneity 
(e.g. O'Brien, Field \& Whittaker 2000). While we expect that habitat heterogeneity should have a positive effect on acacia richness, acacias' tendency to predominate in drier environments (Bouchenak-Khelladi et al. 2010) suggests that their richness may peak not at high, but rather at intermediate productivity (medium precipitation, high precipitation seasonality). A further general driver of diversity is climatic stability through geological time, which should reduce extinction rates, while increasing speciation rates, thereby promoting higher species richness (McGlone 1996). In Africa, this has frequently been discussed, often from a phylogenetic viewpoint, and usually in the context of African rain forests, where it has been proposed that areas that remained relatively stable during past climatic changes retained higher diversity (e.g. Lovett et al. 2005). The effects of long-term climate stability on richness patterns have been less considered for savanna systems (but see Schidelko, Stiels \& Rödder 2011). We use a recently developed variable, climate-change velocity, which measures how fast organisms have had to migrate to successfully track historical climate shifts (Sandel et al. 2011). Low climate-change velocity was expected to promote higher richness in acacias, as it would represent conditions conducive for long-term local survival as well as diversification.

We developed a large database of acacia (Senegalia and Vachellia) locality records that we used to obtain distribution maps for all African acacia species using SDMs. These maps were overlaid to obtain species richness maps, and the factors influencing species richness of the two genera were subsequently assessed; we specifically gauged the relative importance of two sets of general richness determinants, namely current environment (current climate and habitat heterogeneity) and climatic stability through geological time, relative to large-browser diversity as specific potential biotic drivers of acacia richness.

\section{Materials and methods}

The genus Acacia Miller was recently shown to be paraphyletic (Maslin, Miller \& Seigler 2003). For the purpose of this study, we will use the umbrella-term acacia to refer to both newly defined genera that occur in Africa and use the naming convention used by Maslin, Miller \& Seigler (2003) to discuss the genera individually: Senegalia (previously Acacia subg. Aculeiferum) and Vachellia (previously Acacia subg. Acacia).

\section{SPECIES DISTRIBUTION MODELLING}

An extensive database of African acacias was collated (M. Greve, A.M. Lykke, C.W. Fagg, R.E. Gereau, G.P. Lewis, R. Marchant, A.R. Marshall, J. Ndayishimiye, J. Bogaert and J.-C. Svenning, unpublished data) using the free BRAHMS databasing system for botanical data (www.brahmsonline.com/). Database records mainly originated from herbarium data, though some, particularly North African, records are field observations. Data were obtained from various herbarium and personal databases (see Acknowledgements) and georeferenced (Appendix S1A, Table S1 in Supporting Information). Over the years, several acacia species have been renamed, split or lumped; therefore, we used the naming convention of the African Plant Database website (Klopper et al. 2007). Specimens were excluded if uncertainties in plant identity existed because of nomenclatural issues.

We modelled the distribution of acacia species with presences in ten or more grid cells. Forty-three of 49 Senegalia and 49 of 74 Vachellia species had sufficient data to be modelled (Table S1). Modelling was conducted at quarter-degree grid resolution (Appendix S1B) using environmental and spatial variables in Maxent v. 3.3.3e (Phillips, Anderson \& Schapire 2006), one of the bestperforming SDMs for modelling species using presence-only data (Elith \& Leathwick 2007). Nine environmental variables were used to calibrate SDMs. Climatic variables (from Hijmans et al. 2005) that are thought to influence the distribution of plants, and particularly those in savannas (Huntley 1982; Scholes 1997), were selected: annual mean temperature, maximum temperature of the warmest month, mean temperature of the driest quarter, precipitation of the coldest quarter, annual precipitation, precipitation seasonality and precipitation of the driest quarter. In addition, because it has been shown at regional scales that the distributions of acacias are influenced by soil fertility (Scholes \& Walker 1993), soil pH (FAO et al. 2009) was included as a further predictor variable. Finally, trees in savanna systems may be limited by fire (Staver et al. 2009); therefore, a fire intensity index (see Greve et al. 2011), calculated as the number of fire events between 2000 and 2007 (Tansey et al. 2008), was also included as a predictor. All variables were correlated with each other by $r^{2}<0.7$.

Species distributions are not only limited by environmental factors; they may be constrained by factors such as the history of the landscape, biotic interactions or organisms' dispersal abilities (Gaston 2009). For SDMs, spatial filters have been shown to be particularly effective at representing non-environmental constraints across large geographic distances (Blach-Overgaard et al. 2010). Therefore, we also included ten spatial filters in the SDMs (Appendix S1C). The filters were created using SAM v. 4.0 (Rangel, Diniz-Filho \& Bini 2010).

Maxent models were run with presence localities and 10000 background localities from across the African continent. Default Maxent settings were used. The equal training sensitivity and specificity threshold was used to create presence-absence maps for each of the species. This threshold has been shown to perform well (Liu et al. 2005). Although it may result in over-predictions for smaller-ranged species (Freeman \& Moisen 2008), we used presence-absence maps produced with this threshold to produce species richness maps (see below) throughout to remain objective. To evaluate predictive performance of the Maxent models, each species was re-modelled using the same settings, but with fivefold cross-validations (Elith et al. 2011). For the cross-validations, only 5000 background points were used.

\section{SPECIES RICHNESS ANALYSES}

Species richness analyses were conducted at $55 \times 55 \mathrm{~km}$ (approx. $30 \mathrm{~min}$ ) resolution using Lambert Azimuthal equal-area grids to remove possible effects of area on richness (Whittaker, Willis \& Field 2001). Environmental layers were resampled to $55-\mathrm{km}$ resolution using bilinear resampling. Resampling species presence-absence maps (of acacias and browsers) to a coarser resolution could result in distortions in species occurrences (e.g. individual presence cells could be classified as absences because reclassification is carried out on the basis of the majority classification in the new cell). Therefore, each $55-\mathrm{km}$ cell was classified as a presence if at least one finer resolution cell within it contained the species. For the species that could not be modelled, distribution maps were created simply by marking the grid 
cells in which they were recorded as presences. These presenceabsence maps were overlain to produce species richness maps for Senegalia and Vachellia. Species richness analyses were conducted separately for the two genera.

Variation partitioning (Legendre \& Legendre 1998) was used to evaluate how the species richness patterns of Senegalia and Vachellia are affected by (i) browser richness (BROWSERS), (ii) current environment (ENVIRONMENT), and (iii) climate-change velocity (STABILITY). The species richness of large mammals $(\geq 10 \mathrm{~kg}$ ) which have browse as a significant component $(>30 \%)$ of their diet was calculated for Africa (Fig. 2a) based on IUCN distribution maps (IUCN 2009). (See Appendix S1D for more details and a list of browsers.) Distribution maps of the individual species were resampled to $55 \mathrm{~km}$ resolution, as described for acacia richness above.

Climatic factors and habitat heterogeneity were used to represent ENVIRONMENT. Climatic factors, and water and water-energy factors particularly, have consistently been shown to be important predictors of species richness patterns (Hawkins et al. 2003). We therefore initially considered potential evapotranspiration (PET; Ahn \& Tateishi 1994), minimum temperature of the coldest month, annual precipitation and precipitation seasonality (Hijmans et al. 2005) as potential predictors. The interaction between PET and annual precipitation was also included in analyses to represent the interaction between water and energy factors (Appendix S1E). Finally, habitat heterogeneity has been shown to influence the diversity of organisms by creating several environmental niches allowing greater numbers of species to coexist in geographic space (e.g. Thuiller et al. 2006). Therefore, the standard deviation of elevation (The CGIAR Consortium for Spatial Information 2008) within the $55-\mathrm{km}$ grid cells was calculated in ArcGIS to represent habitat variation across the elevation gradient. The elevation data set had a resolution of $1 \mathrm{~km}$.

Climate-change velocity describes the displacement rate of a climate condition over the Earth's surface (Loarie et al. 2009). It is influenced by the rate of change through time and the magnitude of local spatial climate gradients. We calculated velocity (STABILITY) measures for mean annual temperature and mean annual precipitation since the LGM. Palaeoclimate data were obtained from the Paleoclimate Modeling Intercomparison Project Phase II (PMIP-2, Braconnot et al. 2007) (Appendix S1F). The 2.5' resolution Worldclim data (Hijmans et al. 2005) provided estimates of modern mean annual temperature and precipitation. We calculated the spatial climate gradient by taking the slope of these modern climate surfaces. The final products of these calculations were two climate velocity maps (temperature velocity and precipitation velocity).

Soil characteristics have also been proposed to be drivers of species richness (Cowling, Procheş \& Partridge 2009), and acacias are generally thought to favour nutrient-rich soils (Timberlake, Fagg \& Barnes 1999). Therefore, the effect of soil pH (FAO et al. 2009) on species richness was also assessed. However, for both genera, this variable was poorly correlated with species richness $\left(r^{2}<0.03\right)$, and it was therefore not considered in the final analyses.

In analyses conducted across spatial surfaces, spatial autocorrelation may violate the assumption of independence of data points and result in Type I errors (Dormann et al. 2007). Because the richness maps are spatially interpolated, resulting in strong spatial autocorrelation, we subsampled species localities from the species richness grid using a checkerboard-like pattern (Fig. S1). This still left us with a large sample size for both genera $(n=1426$ for Senegalia and $n=1322$ for Vachellia). The reason for the subsampling was (i) to ensure that the non-spatial results were less "distorted" by spatial autocorrelation and (ii) to prevent having to use excessively high $\alpha$ values in the inverse-distance weighted matrix in the models that took spatial autocorrelation into account (see below).

The contribution of each of the above groups of factors (BROWSERS, ENVIRONMENT and STABILITY) to the species richness patterns of African acacias was assessed using multiple linear regressions (OLS). Separate models were constructed for Senegalia and Vachellia to assess the effects of each of the three groups of factors on species richness. Initially, three models of species richness against each of the groups of factors (BROWSERS, ENVIRONMENT, STABILITY) were created. For example, species richness was modelled against the five ENVIRONMENT variables. Quadratic relationships were considered and some predictors required transformation (Appendix S1G). Tolerance values for all predictors were $>0.1$, indicating limited collinearity between variables (Quinn \& Keough 2002). A backward selection procedure which relied on model performance statistics and the distribution of residuals (Appendix S1G) was employed (Zuur et al. 2009).

The above models were also used to conduct variation partitioning (Legendre \& Legendre 1998). In variation partitioning, the unique variation explained by a group of factors and the variation that can be attributed to the combined effect of two or more groups of factors can be separated (Legendre \& Legendre 1998). Here, variation partitioning was thus used to establish how much variation could be explained by each of the following groups of factors: the unique contributions of pure BROWSERS, pure ENVIRONMENT and pure STABILITY; and the shared contributions of BROWSERS-ENVIRONMENT, BROWSERS-STABILITY, ENVIRONMENTSTABILITY, and BROWSERS-ENVIRONMENT-STABILITY (see Lobo, Castro \& Moreno 2001 for more details). Partial $R^{2}$-values representing the above contributions were obtained by subtracting the $R^{2}$-values of models containing one or two of the groups of factors from the $R^{2}$-value of the model containing all three groups of factors, following Heikkinen et al. (2005).

Models of the effects of each of the three groups of factors, and of all factors, on the species richness patterns of the two genera were rerun with $\mathrm{SAR}_{\text {error }}$ models (Kissling \& Carl 2008) in the software SAM v. 4.0 (Rangel, Diniz-Filho \& Bini 2010) to incorporate spatial autocorrelation (Appendix S1H). A backward selection was again used to select variables for the final model, and variation partitioning employed to test how much variation is explained by BROWSERS, ENVIRONMENT and STABILITY factors after the effects of space were removed (Appendix $\mathrm{S} 1 \mathrm{H})$.

Finally, we tested how much of the variation in richness of the two genera could be attributable to factors that drive species richness of both genera, but were not incorporated in the above models. The residuals of the OLS of species richness against the final set of variables selected in the SAR models were extracted for each genus. These residuals were then included as an additional predictor in the whole model SAR analysis of the other genus to represent such 'unknown' factors (cf. Tuomisto, Ruokolainen \& Yli-Halla 2003). The residuals were taken from OLS rather than the SAR model, because in the SAR model the spatial structure is incorporated into the residuals to remove spatial autocorrelation (Tognelli \& Kelt 2004). Since these analyses required using only data points where both genera had occurrences, the sample size for these analyses was somewhat less than that of the other models ( $n=1095$ for both genera). Variation partitioning was again conducted on these data to assess what contribution BROWSERS, ENVIRONMENT and STABILITY factors vs. the residuals of the other genus made in explaining the diversity of the genera (Tuomisto, Ruokolainen \& Yli-Halla 2003). Again, the $R^{2}$-values for the effect of non-spatial factors after the effect of space had been removed from the SAR models were used for variation 
partitioning. For this purpose, we constructed a model of richness against the variables of the whole model (as defined in Table 1), against Vachellia residuals alone (for Senegalia) or Senegalia residuals alone (for Vachellia), and against the combined whole model variables and residuals. Note that the results for the 'whole model' here differed somewhat from those in Table 1 because a smaller data set, which contains only localities where both Senegalia and Vachellia are present (see above), was used for variation partitioning.

Variables were centred and scaled by one standard deviation for OLS and SAR analyses, so that the magnitude of the coefficients could be compared (Schielzeth 2010). Although we report both AIC and $P$-values for richness models, we focus on the results of model selection using AIC rather than $P$-values when considering which variables have an effect on species richness (Burnham \& Anderson 1998).

All GIS analyses were conducted in ArcGIS v. 10 (except the analyses with Hawth's Tools [Appendix S1B], which were run in ArcGIS v. 9.2). The SAR models were run in SAM v. 4.0 (Rangel, Diniz-Filho \& Bini 2010), and any other analyses in R v. 2.12.1 (R Development Core Team 2008).

\section{Results}

The AUC values of SDM models (obtained from fivefold cross-validations) were all above 0.8 , and mostly $>0.9$ (Table S1), indicating that the models performed well.

Species richness maps (Fig. 1) indicate that the two genera have a similar centre of high species richness in the Limpopo Basin, which straddles the borders between Mozambique, South Africa and Zimbabwe. Both genera also show high richness centres in East Africa (see also Marshall et al. in press), though Vachellia species are concentrated along the Eastern Rift of the East African rift system, from where they extend along the eastern edge of the East African plateau. Senegalia's East African centre of richness is located further south-east, extending from Lake Victoria south-east towards the central coastline of Tanzania. Other areas of high species richness for both genera include the Horn of Africa and northern Namibia/southern Angola, and, for Senegalia, possibly eastern Burkina Faso and the regions east thereof. Senegalia also extends into the African wet tropics, which Vachellia does not.

When considering the results of the non-spatial OLS models (Table S2), all three groups of potential drivers (BROWSERS, ENVIRONMENT and STABILITY) contributed to the species richness patterns of both genera. The SAR models (Table 1), which accounted for spatial autocorrelation, indicated that several of the variables that were included in final OLS models actually did not significantly explain acacia richness and that more than half of the variation in richness of both genera was explained by spatial effects. We thus focus on the results of SAR models.

For Senegalia, all three groups of potential drivers contributed to its richness pattern, though the effect of STABILITY was weak (Table 1a). The BROWSERS model alone explained a large fraction of the variation after spatial effects had been factored out - even more than the final model including BROWSERS, ENVIRONMENT and STABILITY effects (Table 1a). (The $R^{2}$-value considered here represents only the variation after space has been removed, which is why the whole model $R^{2}$ is lower than that of the BROWSERS model.) Browser diversity was positively related to richness (Table 1a, Fig. 2b), while amongst the environmental variables, PET and habitat heterogeneity were positively related to richness, and the minimum temperature of the coldest month was negatively related to richness (Table 1a). However, the amount of variation explained by ENVIRONMENT was negligible. Precipitation velocity was negatively related to richness (Table 1a).

Both BROWSERS and ENVIRONMENT models explained significant variation in Vachellia richness, though BROWSERS explained more than twice the variation of ENVIRONMENT (Table 1b). Browser richness was positively related to Vachellia richness (Fig. 2b). Annual precipitation was related to richness with a hump-shaped quadratic relationship, though the effect of precipitation also interacted with PET, while minimum temperature of the coldest month was again negatively related to richness (Table $1 \mathrm{~b}$ ). The richness of Vachellia was not affected by STABILITY in the final model (Table 1b).

Variation partitioning indicated that for Senegalia, the unique contribution of browser diversity was the greatest contributor to the variation in species richness - both for nonspatial and spatial models (Table 2a). As already mentioned above, environmental variables considered here explained virtually no variation in the richness of Senegalia - the contribution of predictors to richness was less for the full model than for the model of browser diversity only in the spatial models (hence the negative values in Table $2 \mathrm{a}$ ). The contribution of STABILITY to Senegalia richness was also small. In contrast, the unique contribution of environmental factors to Vachellia richness was bigger, though less in the spatial than the nonspatial models. However, the unique contribution of browser diversity still contributed most to the Vachellia model.

Adding the Vachellia or Senegalia model residuals to the species richness model of the other genus indicated that factors not considered in the analyses could also be affecting the richness patterns of African acacias. For both Senegalia and Vachellia, including the other genus' OLS residuals in the equation resulted in a substantial increase in the $R^{2}$-values of the non-spatial component of the model (Tables 1 and $2 b$ ). The $R^{2}$-value of the whole model with Vachellia or Senegalia residuals was greater than the sum of the $R^{2}$-values of the whole model without the residuals and the model containing only the residuals. This explains the negative $V_{\mathrm{FR}}$ values in Table $2 b$ and indicates that the effect of these other factors (i.e. the factors represented by the other genus' residuals) was dependent on the other predictors considered in the model. Noteworthy is, however, that even when these residuals were entered into the analyses, browser diversity still emerged as an important predictor of richness (Table 1).

For both genera, much of the variation in richness appeared to be explained by spatial signal alone. The $R^{2}$-values representing only the contribution of the predictors after the effect of space has been removed were less than half (and sometimes 


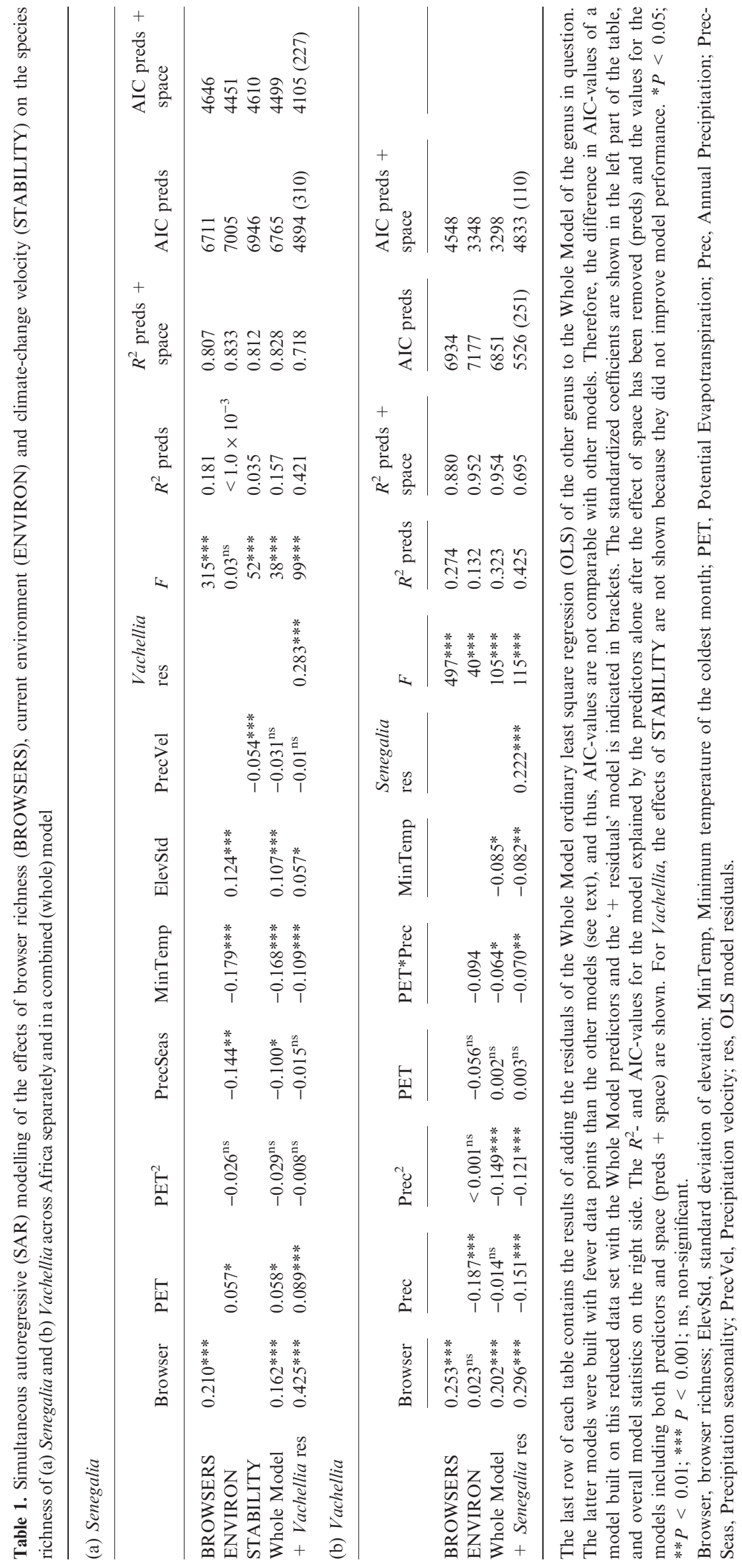



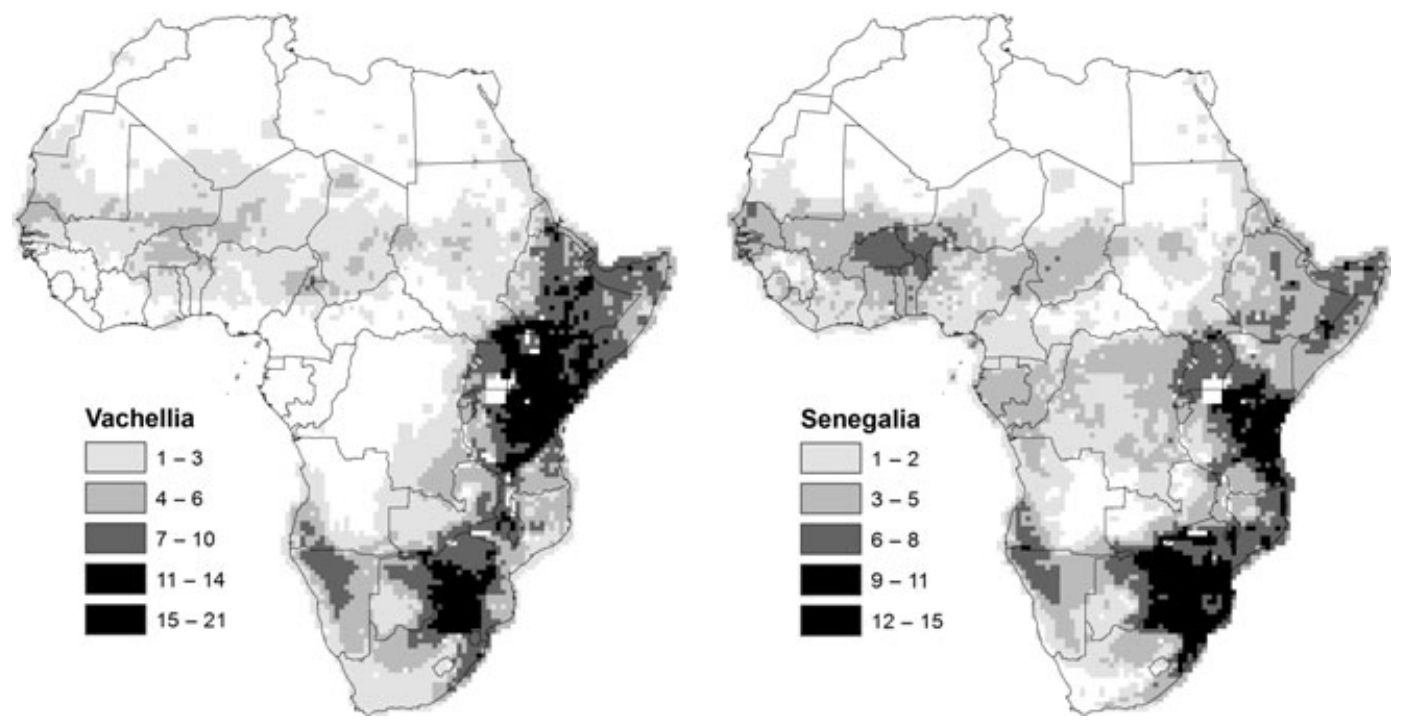

Fig. 1. Species richness maps of Senegalia and Vachellia in Africa.
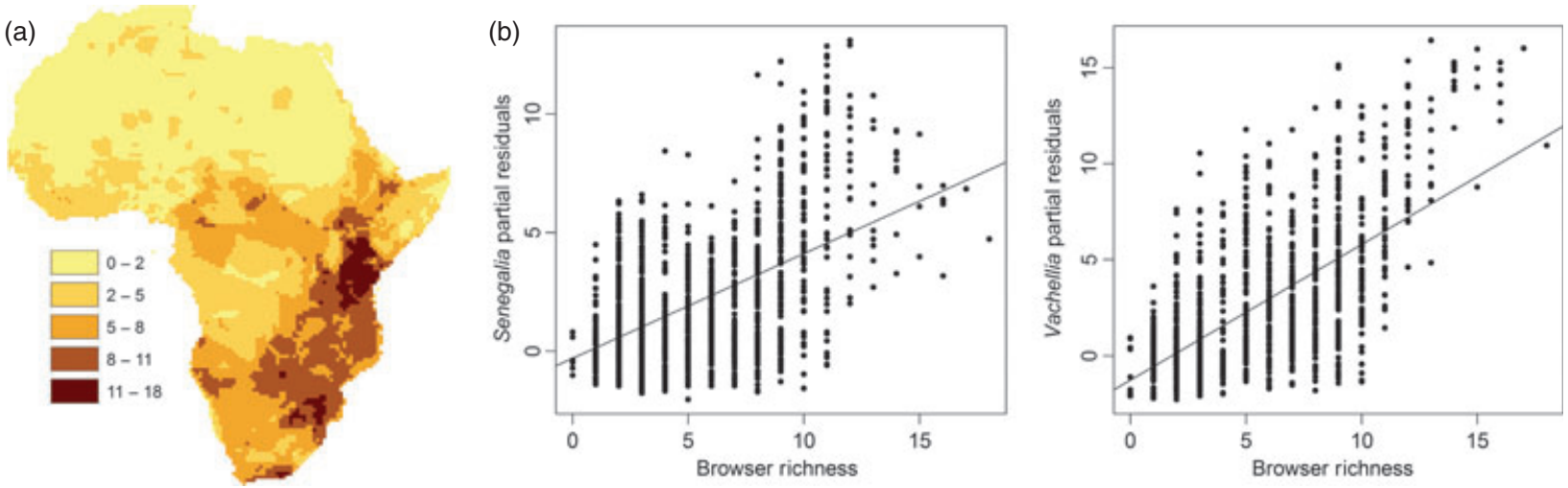

Fig. 2. (a) Map of large ( $\geq 10 \mathrm{~kg}$ ) mammalian browser species richness across Africa, compiled from the list of browsers in Appendix S1D. (b) Partial residual plots showing the effect of browser diversity on the species richness of Senegalia and Vachellia after controlling for the effects of the other variables in multiple linear regressions.

less than a third) of the contribution of the combined ecological and spatial effects (Table 2a). Thus, combined ecological and spatial effects were particularly successful at predicting the richness patterns of the two genera, with $R^{2}$-values exceeding 0.8 (Table 1).

\section{Discussion}

The effect of biotic influences on species richness patterns have been poorly assessed at large spatial scales. Here, we used distribution modelling to map the distribution of Senegalia and Vachellia species, and the species richness patterns for these two genera, across the African continent. For these genera, factors that usually best explain species richness patterns have less explanatory power than factors seldom considered in richness analyses. Most significantly, we show - for the first time to our knowledge - that consumer diversity may be a key driver of richness at macroecological scale.
Senegalia and Vachellia possess two main, and similar, centres of diversity (Fig. 1). Across Africa, Senegalia is more widely distributed than Vachellia, and their richness patterns differ to such an extent that the factors that best explain the two genera's distributions differ considerably. Only browser diversity is a common explanatory variable to both models. In addition, the amount of variation explained by the three groups of factors (ENVIRONMENT, BROWSERS and STABILITY) differs between the genera. Senegalia's wider distribution across Africa, particularly into the wet tropics, may be ascribed to the fact that the genus' presence in Africa is attributable to at least two immigration events to the continent, with one clade diversifying in open environments, and the other, smaller, clade in the moister forested parts of the continent (Bouchenak-Khelladi et al. 2010). In Africa, the forest-adapted clade within Senegalia is relatively species-poor (maximally 13 species, Ross 1979; Bouchenak-Khelladi et al. 2010; the lack of an updated phylogeny makes it difficult to 
Table 2. (a) Partitioning of the amount of variation in species richness of Senegalia and Vachellia that can be attributed to pure browser richness $\left(\mathrm{V}_{\mathrm{B}}\right)$, current environment $\left(\mathrm{V}_{\mathrm{E}}\right)$, climate velocity $\left(\mathrm{V}_{\mathrm{V}}\right)$, and the combined effects of browser richness and current environment $\left(\mathrm{V}_{\mathrm{BE}}\right)$, browser richness and climate velocity $\left(\mathrm{V}_{\mathrm{BV}}\right)$, current environment and climate velocity $\left(\mathrm{V}_{\mathrm{EV}}\right)$, and browser richness, current environment and climate velocity $\left(\mathrm{V}_{\mathrm{EBV}}\right)$. Variation partitioning results are shown for ordinary least square (OLS) models, which assume independence of all data points regardless of their spatial position, and for the environmental contribution of simultaneous autoregression (SAR) models after the effect of space on the models has been factored out ( $R^{2}$ preds in Table 1). The best SAR model for Vachellia excluded climate velocity variables; therefore, only the contribution of the other two sets of variables is shown. (b) The amount of variation in species richness of Senegalia and Vachellia that can be attributed to the variables of the 'Whole Model' in (a) $\left(V_{W}\right)$, to the residuals of the whole model OLS of the other genus $\left(V_{R}\right)$, and to the combined contribution of the two $\left(\mathrm{V}_{\mathrm{WR}}\right)$. For both (a) and (b), total variation explained by all variables considered is given by $\mathrm{R}_{\mathrm{TOT}}$

(a)

\begin{tabular}{llllllllll}
\hline Genus & Model & $\mathrm{V}_{\mathrm{B}}$ & $\mathrm{V}_{\mathrm{E}}$ & $\mathrm{V}_{\mathrm{V}}$ & $\mathrm{V}_{\mathrm{BE}}$ & $\mathrm{V}_{\mathrm{BV}}$ & $\mathrm{V}_{\mathrm{EV}}$ & $\mathrm{V}_{\text {EBV }}$ & $\mathrm{R}_{\mathrm{TOT}}$ \\
\hline Senegalia & OLS & 0.142 & 0.066 & 0.023 & 0.068 & 0.027 & 0.030 & 0.050 & 0.407 \\
& SAR & 0.148 & -0.047 & 0.020 & 0.021 & -0.011 & 0.003 & 0.023 & 0.157 \\
Vachellia & OLS & 0.192 & 0.170 & 0.012 & 0.106 & 0.011 & 0.031 & 0.136 & 0.659 \\
& SAR & 0.191 & 0.049 & 0.083 & 0.323 & & & &
\end{tabular}

(b)

\begin{tabular}{llllll}
\hline Genus & Model & $\mathrm{V}_{\mathrm{W}}$ & $\mathrm{V}_{\mathrm{R}}$ & $\mathrm{V}_{\mathrm{WR}}$ & $\mathrm{R}_{\mathrm{TOT}}$ \\
\hline Senegalia & SAR & 0.316 & 0.191 & -0.086 & 0.421 \\
Vachellia & SAR & 0.348 & 0.150 & -0.073 & 0.425 \\
\hline
\end{tabular}

quantify the exact number of species in the clade) compared with the open-environment clade within Senegalia. The two independent colonization events into Africa of Senegalia clades adapted to different environments may at least partly explain why ENVIRONMENT explains virtually no variation in the richness of the genus. In contrast to Senegalia, the African Vachellia are thought to originate from a single openenvironment African ancestor (Bouchenak-Khelladi et al. 2010). One could thus expect that, if environmental preferences are heritable (for which Bouchenak-Khelladi et al. 2010 provide evidence), Vachellia richness should be considerably better predicted by the environment, which is what we find here (Table 1).

That herbivory has significant effects on African acacias is well-established (references in Introduction). However, it is noteworthy that plant species richness could be so well predicted by browser diversity, which emerges as the strongest predictor of richness for both acacia genera. Previous tests on the effects of herbivore species richness on plants have mainly been considered at community level and shown contradictory results (reviewed in Hester et al. 2002).

How browsers may facilitate higher acacia species richness at continental scale is difficult to elucidate (Kissling, Rahbek \& Böhning-Gaese 2007). It is known that plant-insect herbivore interactions frequently result in evolutionary arms races, which are thought to be behind the frequently highly concordant richness of both insects and plant species (Futuyma \& Agrawal 2009). However, mammalian herbivores, which have probably exerted the greatest herbivory pressure on acacias over evolutionary time (Maclean et al. 2011), tend to have more generalist food requirements than insects, and evolutionary arms races may thus be weaker in plant-large mammal herbivore interactions than in plant-insect interactions (Prins et al. 2006; Futuyma \& Agrawal 2009). Therefore, plant-consumer associations between individual acacia species and browser species may not directly drive concordant richness of the two groups.

Decreased fitness of acacias because of browsing could be an alternative mechanism governing the genera's richness patterns. While acacias are well adapted to herbivory, herbivory defence and tolerance come at a cost to the plants: their reproductive output directly decreases through reduced or non-existent fruit production (Fornara \& du Toit 2007; Staver et al. 2009), seedling survival (Maclean et al. 2011) and adult survival and growth (Maclean et al. 2011), which leads to decreased tree densities (Staver et al. 2009). The fact that several phenotypic responses to browsing are less pronounced under low browsing pressure (Fornara \& du Toit 2007) further indicates that these responses are initiated at a cost to the plant. The competitive ability and fitness of acacias exposed to high herbivory may thus be reduced (assuming that high browser diversity is also related to high herbivory pressure), resulting in fewer offspring and less gene flow. This may diminish competition and facilitate coexistence of closely related species, though mainly if herbivore pressure affects dominant rather than inferior species (Hulme 1996). Therefore, species which evolved allopatrically may come to coexist because of secondary dispersal (e.g. Gehrke \& Linder 2011). Alternatively, this could promote habitat specialization or genetic drift because the gene pool across the range of a species is not swamped by dominant genes (Fine et al. 2006), which may eventually culminate in speciation (McPeek 1996). In support of this, many widespread African acacias show much trait variation across their range, so that individuals from two distributional extremes appear to be different species, but are classified as a single species because intermediate forms exist (e.g. Acacia senegal and Acacia oliveri; Thulin 1993). In addition, amongst coexisting acacias, some species may be more palatable than others, 
resulting in lower recruitment of the more palatable than the less palatable species (Bond, Smythe \& Balfour 2001). The trade-off between investments in growth (of more palatable species) vs. defence (of less palatable species) could thus favour coexistence under higher browsing pressure.

As already mentioned, current environment alone predicts a significant amount of variation in Vachellia's richness. This, together with the fact that the effects of environment on Vachellia richness were not as substantial as they often are in other groups (Hawkins et al. 2003; Field et al. 2009), suggests that, while most acacias have a preference for more arid environments (Bouchenak-Khelladi et al. 2010), environmental preferences may not be strongly conserved within this range of climatic conditions, that is, the group may display a lack of niche conservatism (with 'niche' in this context denoting the environmental niche). Otherwise, the effects of current environment on Vachellia richness are as expected. Annual precipitation is quadratically related to richness, although its influence is dependent on PET, indicating that productivity (encompassing both energy and water dynamics) affects the richness of the group. In addition, richness decreases with minimum temperature of the coldest quarter, showing that acacia richness may be restricted by cold temperatures.

Climate-change velocity is only a weak predictor of Senegalia richness, with stability (low velocity) in precipitation predicting higher species richness. Various other studies have found that climate stability promotes species diversity (e.g. Jansson 2003; Sandel et al. 2011). Because acacias are adapted to drier and seasonal environments, glacial periods that were characterized by even drier and more seasonal environments may have had relatively little effect on the diversity of the group. Importantly, African savannas were more extensive during the long-lived glacial periods than they are at present (Morley 2000), suggesting that today's savannas may, at least partly, be 'remnants' of the savannas that reached maximum extent during the LGM. Therefore, if range shifts of acacias did occur because of post-LGM warming, they may well have involved extinctions from areas where the group no longer occurs, rather than recolonizations of previously unfavourable areas by secondary dispersal from areas where species persisted. In addition, climate-change velocity represents the difference between current and LGM climates while taking topography into account, but ignores climate oscillations between the LGM and the present, and late Tertiary climate changes, the period during which much of the diversification of the two genera occurred (Bouchenak-Khelladi et al. 2010).

There were strong patterns in acacia richness that were neither explained by browser richness, current environment nor long-term climate stability. Notably, the species richness of one genus (even after accounting for its correlations to browser richness, current environment, and climate stability) explained important amounts of variation in the species richness of the other genus $(60 \%$ and $40 \%$ of the variation explained by the other three groups of factors for Senegalia and Vachellia, repectively). This suggests that some variable(s) not considered here have consistently affected the diversity pattern of both plant genera (cf. Tuomisto, Ruokolainen \& Yli-Halla 2003), although what precisely these might be is impossible to elucidate here. They could, for example, be factors that have an effect at finer scales than have been measured here, occurred locally (e.g. what allowed both genera to reach such diversity within the Limpopo Basin?), or be factors that have not been accurately mapped, such as soils and geology, fire, pollinator availability or diversity, seed dispersers, or even aspects of long-term faunal dynamics not captured by current patterns of browser richness (Martin 1966; Faith et al. 2011).

Even when accounting for the species richness of the other genus, there are unexplained spatial patterns in the richness of both acacia genera. Whatever drives these patterns must represent factors which affect the two genera differently. For example, some Vachellia species form symbiotic relationships with ants, with ants providing varying degrees of defence against herbivory to trees, and trees providing nests for the ants (Ross 1979; Palmer et al. 2008). This three-way biotic interaction may thus have affected distribution and diversity patterns of Vachellia. Furthermore, information on the evolutionary relationships between species and ages of the taxa in the two genera (information which is currently not available for most acacias, Bouchenak-Khelladi et al. 2010) could shed light on the role of historical factors on the diversification of the two genera (e.g. Gehrke \& Linder 2011).

\section{LIMITATIONS AND CONSIDERATIONS}

Several sources of error could have arisen in the analyses here. First, although SDMs performed relatively well in predicting the distributions of most species, inaccuracies in the maps will have arisen due to various factors. Some regions have been under-collected, resulting in potential distribution biases. Moreover, factors such as historical biogeography, dispersal barriers, and speciation because of range fragmentation would not have been entirely represented in SDMs. Finally, imprecisions in the projections of SDMs would have resulted in overor underpredictions of some distributions and thus also inaccuracies and interpolation of the species richness maps.

The taxonomy of some acacias may also need revising. In the age of molecular phylogenetics, African acacias have received little attention and some of the subspecies and varieties might, for example, have to be elevated to species level. This might affect the delimitations of species distribution, although richness maps might not have been affected much, as many of the subspecies and varieties are allopatric.

Finally, a correlation between plant richness and other factors, for example, browser diversity, does not necessarily mean that one drives the other. Correlations could also be due to a third factor influencing the diversity of both factors. When including a range of environmental variables in models, browser diversity alone explained most of the non-spatial variation in the richness of both plant genera (Tables 1 and S2); therefore, we have confidence that browsers really do affect acacia richness to some extent. Other authors have argued that woody plant diversity drives mammal and bird diversity (Kissling, Rahbek \& Böhning-Gaese 2007; Qian et al. 2009), 
whereas we argue that browser diversity could drive variation in the diversity of plants. We believe that, in this case, the reverse argument - that the species richness of acacias alone should be able to predict much of the richness patterns of large herbivores - is less likely. For one, this would imply that individual plant genera drove the diversification of African browsers. Given the often patchy nature of savannas (du Toit \& Cumming 1999), the fact that savannas support many woody species other than acacias, and the tendency for browsers to have generalist dietary requirements (e.g. Prins et al. 2006), this scenario seems less likely. In addition, modern African bovids, which constitute a significant proportion of browsers, diversified during the middle-late Miocene (Janis 1993), which is prior to the origin of many acacia species (BouchenakKhelladi et al. 2010) (though there would be turnover of browser assemblages with climate changes through subsequent periods of climate change, Janis 1993). Finally, the range of adaptations of acacias to herbivory by large herbivores is extensive, indicating that much of the evolution of the group has been driven by mammalian herbivory.

\section{Conclusion}

The effects of different factors on species richness patterns may depend on the spatial scale and extent of the study being conducted (Willig, Kaufman \& Stevens 2003; Field et al. 2009), the functional characteristics of the organisms (Hawkins, Rodríguez \& Weller 2011) and habitat (Field et al. 2009). Here, we find that the factors that often correlate highly with species richness of clades at higher taxonomic levels do not explain most of the variation in acacia richness in Africa; yet consumer diversity, a factor otherwise seldom considered in richness analyses, explains much of the variation of the group. This 'anomaly' may be related to the functional characteristics (adaptations to herbivory) of the genera (Hawkins, Rodríguez \& Weller 2011). Biotic factors have not often been considered in examining the drivers of richness patterns: besides tests of the congruence of resource-consumer diversity patterns, with resources and consumers usually comprising plants and animals, respectively (Kissling, Rahbek \& Böhning-Gaese 2007; Qian et al. 2009), it has also been suggested that the discrepancy between 'fundamental' (the number of species predicted by abiotic factors) and 'realized' (the observed) species richness may be a result of biotic interactions (Violle et al. 2011).

Africa is unique in that large mammal species have mainly continued to coexist with humans over the last millennia (Owen-Smith 1989). However, large herbivore populations have declined, or been locally exterminated, across extensive regions of the continent in the last century, and the biotic interactions between herbivores and vegetation will therefore have been altered, or even disappeared (Spinage 1973; Owen-Smith 1989). Herbivory, previously a main agent in the evolution of acacias, may thus cease to act as a major adaptive pressure in such landscapes (although in some regions, e.g., goats and sheep may assume the ecological role of browsers, Groen et al. 2011). The retention of large herbivores is thus not only essen- tial for retaining ecological (Marchant 2010), but also evolutionary functionality in African savannas.

\section{Acknowledgements}

Special thanks to Denis Filer who provided assistance with databasing the herbarium records in the BRAHMS database management system for botanical data. The following are thanked for providing acacia data: the FLOTROP database (especially Philippe Daget), Roy Gereau, the West African Vegetation Database (http://www.westafricanvegetation.senckenberg.de), the South African National Biodiversity Institute; the Senckenberg Research Institute, Uppsala University, Université Libre de Bruxelles, Wageningen, and the University of Dar es Salaam Herbaria; GBIF (http://data.gbif.org/datasets/ resource/621); the National Museums of Kenya; National Herbarium of Tanzania; National Herbarium of Namibia (specimen database: SPMNDB; National Botanical Research Institute); and National Botanical Garden of Belgium. The Royal Botanic Gardens, Kew; London Natural History Museum; Coimbra; and Lisbon Herbaria are also thanked for providing MG access to their collections. Brett Murphy kindly provided assistance with statistical analyses. International climate modelling groups are thanked for providing their data for analysis and the Laboratoire des Sciences du Climat et de l'Environnement for collecting and archiving the palaeoclimate model data. Peder Klith Bøcher provided assistance with GIS analyses. The following sources provided funding: the Danish Council for Independent Research - Natural Sciences, grant 272-07-0242 (JCS and MG); the Undesert Project, EU-FP7 243906 (AML and MS); the Liz Claiborne Art Ortenburg Foundation with the African Conservation Centre, Nairobi (RG and RM); and BRIC of the Université Libre de Bruxelles and the Belgian Technical Cooperation (JN).

\section{References}

Ahn, C.-H. \& Tateishi, R. (1994) Development of a global 30-minute grid potential evapotranspiration data set. Journal of the Japan Society Photogrammetry Remote Sensing, 33, 12-21.

Araújo, M.B. \& Luoto, M. (2007) The importance of biotic interactions for modelling species distributions under climate change. Global Ecology and Biogeography, 16, 743-753.

Blach-Overgaard, A., Svenning, J.-C., Dransfield, J., Greve, M. \& Balslev, H. (2010) Determinants of palm species distributions across Africa: the relative roles of climate, non-climatic environmental factors, and spatial constraints. Ecography, 33, 380-391.

Bond, W.J., Smythe, K.A. \& Balfour, D.A. (2001) Acacia species turnover in space and time in an African savanna. Journal of Biogeography, 28, 117-128.

Bouchenak-Khelladi, Y., Maurin, O., Hurter, J. \& van der Bank, M. (2010) The evolutionary history and biogeography of Mimosoideae (Leguminosae): an emphasis on African acacias. Molecular Phylogenetics and Evolution, 57, 495-508.

Braconnot, P., Otto-Bliesner, B., Harrison, S., Joussaume, S., Peterchmitt, J.-Y., Abe-Ouchi, A. et al. (2007) Results of PMIP2 coupled simulations of the Mid-Holocene and Last Glacial Maximum - Part 1: experiments and largescale features. Climate of the Past, 3, 261-277.

Burnham, K.P. \& Anderson, D.R. (1998) Model Selection and Multimodel Inference, 2nd edn. Springer-Verlag, New York.

Cooper, S.M. \& Owen-Smith, N. (1985) Condensed tannins deter feeding by browsing ruminants in a South African savanna. Oecologia, 67, 142-146.

Cooper, S.M. \& Owen-Smith, N. (1986) Effects of plant spinescence on large mammalian herbivores. Oecologia, 68, 446-455.

Cowling, R.M., Proches, S. \& Partridge, T.C. (2009) Explaining the uniqueness of the Cape flora: incorporating geomorphic evolution as a factor for explaining its diversification. Molecular Phylogenetics and Evolution, 51, 64-74.

Cumming, D.H.M. (1982) The influence of large herbivores on savanna structure in Africa. Ecology of Tropical Savannas (eds B.J. Huntley \& B.H. Walker), pp. 217-245. Springer-Verlag, Berlin.

Dormann, C.F., McPherson, J.M., Araújo, M.B., Bivand, R., Bolliger, J., Carl, G. et al. (2007) Methods to account for spatial autocorrelation in the analysis of species distributional data: a review. Ecography, 30, 609-628.

Elith, J. \& Leathwick, J. (2007) Predicting species distributions from museum and herbarium records using multiresponse models fitted with multivariate adaptive regression splines. Diversity and Distributions, 13, 265-275.

Elith, J., Phillips, S.J., Hastie, T., Dudík, M., Chee, Y.E. \& Yates, C.J. (2011) A statistical explanation of MaxEnt for ecologists. Diversity and Distributions, 17, 43-57. 
Faith, J.T., Choiniere, J.N., Tryon, C.A., Peppe, D.J. \& Fox, D.L. (2011) Taxonomic status and paleoecology of Rusingoryx atopocranion (Mammalia, Artiodactyla), an extinct Pleistocene bovid from Rusinga Island, Kenya. Quaternary Research, 75, 697-707.

FAO, IIASA, ISRIC, ISSCAS \& JRC (2009) Harmonized World Soil Database. FAO and IIASA, Rome and Laxenburg.

Field, R., Hawkins, B.A., Cornell, H.V., Currie, D.J., Diniz-Filho, J.A.F., Guegan, J.F., Kaufman, D.M., Kerr, J.T., Mittelbach, G.G., Oberdorff, T., O'Brien, E.M. \& Turner, J.R.G. (2009) Spatial species-richness gradients across scales: a meta-analysis. Journal of Biogeography, 36, 132-147.

Fine, P.V.A., Miller, Z.J., Mesones, I., Irazuzta, S., Appel, H.M., Stevens, M.H.H., Sääksjärvi, I., Schultz, J.C. \& Coley, P.D. (2006) The growthdefense trade-off and habitat specialization by plants in Amazonian forests. Ecology, 87, 150-162.

Fornara, D.A. \& du Toit, J.T. (2007) Browsing lawns? Responses of Acacia nigrescens to ungulate browsing in an African savanna. Ecology, 88, 200-209.

Freeman, E.A. \& Moisen, G.G. (2008) A comparison of the performance of threshold criteria for binary classification in terms of predicted prevalence and kappa. Ecological Modelling, 217, 48-58.

Futuyma, D.J. \& Agrawal, A.A. (2009) Macroevolution and the biological diversity of plants and herbivores. Proceedings of the National Academy of Sciences of the United States of America, 106, 18054-18061.

Gaston, K.J. (2009) Geographic range limits: achieving synthesis. Proceedings of the Royal Society B, 276, 1395-1406.

Gehrke, B. \& Linder, H.P. (2011) Time, space and ecology: why some clades have more species than others. Journal of Biogeography, 38, 1948-1962.

Greve, M., Lykke, A.M., Blach-Overgaard, A. \& Svenning, J.-C. (2011) Environmental and anthropogenic determinants of vegetation distribution across Africa. Global Ecology and Biogeography, 20, 661-674.

Groen, T.A., van Langevelde, F., van de Vijver, C.A.D.M., de Raad, A.L., de Leeuw, J. \& Prins, H.H.T. (2011) A continental analysis of correlations between tree patterns in African savannas and human and environmental variables. Journal of Arid Environments, 75, 724-733.

Hawkins, B.A., Rodríguez, M.Á. \& Weller, S.G. (2011) Global angiosperm family richness revisited: linking ecology and evolution to climate. Journal of Biogeography, 38, 1253-1266.

Hawkins, B.A., Field, R., Cornell, H.V., Currie, D.J., Guégan, J.F., Kaufman, D.M., Kerr, J.T., Mittelbach, G.G., Oberdorff, T., O’Brien, E.M., Porter, E.E. \& Turner, J.R.G. (2003) Energy, water, and broad-scale geographic patterns of species richness. Ecology, 84, 3105-3117.

Heikkinen, R.K., Luoto, M., Kuussaari, M. \& Pöyry, J. (2005) New insights into butterfly-environment relationships using partitioning methods. Proceedings of the Royal Society B, 272, 2203-2210.

Hester, A.J., Bergman, M., Iason, G.R. \& Moen, J. (2002) Impacts of large herbivores on plant community structure and dynamics. Large Herbivore Ecology and Ecosystem and Conservation (eds K. Danell, P. Duncan, R. Bergström \& J. Pastor), pp. 97-141. Cambridge University Press, West Nyack, NY, USA.

Hijmans, R.J., Cameron, S.E., Parra, J.L., Jones, P.G. \& Jarvis, A. (2005) Very high resolution interpolated climate surfaces for global land areas. International Journal of Climatology, 25, 1965-1978.

Hulme, P.E. (1996) Herbivory, plant regeneration, and species coexistence. Journal of Ecology, 84, 609-615.

Huntley, B.J. (1982) Southern African savannas. Ecology of Tropical Savannas (eds B.J. Huntley \& B.H. Walker), pp. 101-119. Springer-Verlag, Berlin.

IUCN (2009) IUCN Red List of Threatened Species. Version 2009.1.

Janis, C.M. (1993) Tertiary mammal evolution in the context of changing climates, vegetation, and tectonic events. Annual Review of Ecology and Systematics, 24, 467-500.

Jansson, R. (2003) Global patterns in endemism explained by past climatic change. Proceedings of the Royal Society of London B, 270, 583-590.

Jetz, W., Kreft, H., Ceballos, G. \& Mutke, J. (2009) Global associations between terrestrial producer and vertebrate consumer diversity. Proceedings of the Royal Society B, 276, 269-278.

Kissling, W.D. \& Carl, G. (2008) Spatial autocorrelation and the selection of simultaneous autoregressive models. Global Ecology and Biogeography, 17, $59-71$.

Kissling, W.D., Rahbek, C. \& Böhning-Gaese, K. (2007) Food plant diversity as broad-scale determinant of avian frugivore richness. Proceedings of the Royal Society B, 274, 799-808.

Klopper, R.R., Gautier, L., Chatelain, C., Smith, G.F. \& Spichiger, R. (2007) Floristics of the angiosperm flora of sub-Saharan Africa: an analysis of the African Plant Checklist and Database. Taxon, 56, 201-208.

Legendre, L. \& Legendre, P. (1998) Numerical Ecology, 1st edn. Elsevier, Amsterdam.
Liu, C., Berry, P.M., Dawson, T.P. \& Pearson, R.G. (2005) Selecting thresholds of occurrence in the prediction of species distributions. Ecography, 28, 385393

Loarie, S.R., Duffy, P.B., Hamilton, H., Asner, G.P., Field, C.B. \& Ackerly, D.D. (2009) The velocity of climate change. Nature, 462, 1052-U1111.

Lobo, J.M., Castro, I. \& Moreno, J.C. (2001) Spatial and environmental determinants of vascular plant species richness distribution in the Iberian Peninsula and Balearic Islands. Biological Journal of the Linnean Society, 73, 233 253.

Lovett, J.C., Marchant, R., Taplin, J. \& Küper, W. (2005) The oldest rainforests in Africa: stability or resilience for survival and diversity? Phylogeny and Conservation (eds A. Purvis, J.L. Gittleman \& T. Brooks), pp. 198-229. Cambridge University Press, Cambridge.

Maclean, J.E., Goheen, J.R., Doak, D.F., Palmer, T.M. \& Young, T.P. (2011) Cryptic herbivores mediate the strength and form of ungulate impacts on a long-lived savanna tree. Ecology, 92, 1626-1636.

Marchant, R. (2010) Understanding complexity in savannas: climate, biodiversity and people. Current Opinion in Environmental Sustainability, 2, 101-108.

Marshall, A.R., Platts, P.J., Gereau, R.E., Kindeketa, W., Kang'ethe, S. \& Marchant, R. (in press) The genus Acacia (Fabaceae) in East Africa: distribution, biodiversity and the protected area network. Plant Ecology and Evolution.

Martin, P.S. (1966) Africa and Pleistocene overkill. Nature, 212, 339-342.

Maslin, B.R., Miller, J.T. \& Seigler, D.S. (2003) Overview of the generic status of Acacia (Leguminosae : Mimosoideae). Australian Systematic Botany, 16, $1-18$.

McGill, B.J. (2010) Matters of scale. Science, 328, 575-576.

McGlone, M.S. (1996) When history matters: scale, time, climate and tree diversity. Global Ecology and Biogeography Letters, 5, 309-314.

McPeek, M.A. (1996) Linking local species interactions to rates of speciation in communities. Ecology, 77, 1355-1366.

Milewski, A.V. \& Madden, D. (2006) Interactions between large African browsers and thorny Acacia on a wildlife ranch in Kenya. African Journal of Ecology, 44, 515-522.

Morley, R.J. (2000) Origin and Evolution of Tropical Rain Forests, 1st edn. John Wiley \& Sons. Ltd, Chichester.

O'Brien, E.M., Field, R. \& Whittaker, R.J. (2000) Climatic gradients in woody plant (tree and shrub) diversity: water-energy dynamics, residual variation, and topography. Oikos, 89, 588-600.

Owen-Smith, N. (1989) Megafaunal extinctions: the conservation message from 11,000 years B.P. Conservation Biology, 3, 405-412.

Palmer, T.M., Stanton, M.L., Young, T.P., Goheen, J.R., Pringle, R.M. \& Karban, R. (2008) Breakdown of an ant-plant mutualism follows the loss of large herbivores from an African savanna. Science, 319, 192-195.

Phillips, S.J., Anderson, R.P. \& Schapire, R.E. (2006) Maximum entropy modeling of species geographic distributions. Ecological Modelling, 190, 231-259.

Prins, H.H.T., de Boer, W.F., van Oeveren, H., Correia, A., Mafuca, J. \& Olff, H. (2006) Co-existence and niche segregation of three small bovid species in southern Mozambique. African Journal of Ecology, 44, 186-198.

Qian, H., Kissling, W.D., Wang, X. \& Andrews, P. (2009) Effects of woody plant species richness on mammal species richness in southern Africa. Journal of Biogeography, 36, 1685-1697.

Quinn, G.P. \& Keough, M.J. (2002) Experimental Design and Data Analysis for Biologists, 1st edn. Cambridge University Press, Cambridge.

R Development Core Team (2008) R: a language and environment for statistical computing, version 2.8.1. R Foundation for Statistical Computing, Vienna.

Rangel, T.F., Diniz-Filho, J.A.F. \& Bini, L.M. (2010) SAM: a comprehensive application for Spatial Analysis in Macroecology. Ecography, 33, 46-50.

Ross, J.H. (1979) A conspectus of the African Acacia species. Memoirs of the Botanical Survey of South Africa, 44, 1-155.

Sandel, B., Arge, L., Dalsgaard, B., Davies, R.G., Gaston, K.J., Sutherland, W.J. \& Svenning, J.-C. (2011) The influence of Late Quaternary climatechange velocity on species endemism. Science, 334, 660-664.

Schidelko, K., Stiels, D. \& Rödder, D. (2011) Historical stability of diversity patterns in African estrildid finches (Aves: Estrildidae)? Biological Journal of the Linnean Society, 102, 455-470.

Schielzeth, H. (2010) Simple means to improve the interpretability of regression coefficients. Methods in Ecology and Evolution, 1, 103-113.

Scholes, R.J. (1997) Savanna. Vegetation of Southern Africa (eds R.M. Cowling, D.M. Richardson \& S.M. Pierce), pp. 258-277. Cambridge University Press, Cambridge.

Scholes, R.J. \& Walker, B.H. (1993) An African Savanna, 1st edn. Cambridge University Press, Cambridge. 
Spinage, C.A. (1973) A review of ivory exploitation and elephant population trends in Africa. African Journal of Ecology, 11, 281-289.

Staver, A.C., Bond, W.J., Stock, W.D., van Rensburg, S.J. \& Waldram, M.S (2009) Browsing and fire interact to suppress tree density in an African savanna. Ecological Applications, 19, 1909-1919.

Tansey, K., Gregoire, J.M., Defourny, P., Leigh, R., Pekel, J.F.O., van Bogaert, E. \& Bartholome, E. (2008) A new, global, multi-annual (2000-2007) burnt area product at $1 \mathrm{~km}$ resolution. Geophysical Research Letters, 35, L01401.

The CGIAR Consortium for Spatial Information (2008) SRTM $1 \mathrm{~km}$ Digital Elevation Data.

Thuiller, W., Midgley, G.F., Rouget, M. \& Cowling, R.M. (2006) Predicting patterns of plant species richness in megadiverse South Africa. Ecography, 29, 733-744.

Thulin, M. (1993) Flora of Somalia. The Royal Botanic Gardens, Kew.

Timberlake, J., Fagg, C.W. \& Barnes, R. (1999) Field Guide to the Acacias of Zimbabwe, 1st edn. CBC Publishing, Harare.

Tognelli, M.F. \& Kelt, D.A. (2004) Analysis of determinants of mammalian species richness in South America using spatial autoregressive models. Ecography, 27, 427-436.

du Toit, J.T. \& Cumming, D.H.M. (1999) Functional significance of ungulate diversity in African savannas and the ecological implications of the spread of pastoralism. Biodiversity and Conservation, 8, 1643-1661.

Tuomisto, H., Ruokolainen, K. \& Yli-Halla, M. (2003) Dispersal, environment, and floristic variation of western Amazonian forests. Science, 299 241-244.

Violle, C., Bonis, A., Plantegenest, M., Cudennec, C., Damgaard, C., Marion, B., Le Cœur, D. \& Bouzillé, J.-B. (2011) Plant functional traits capture species richness variations along a flooding gradient. Oikos, 120, 389-398.

Whittaker, R.J., Willis, K.J. \& Field, R. (2001) Scale and species richness: towards a general, hierarchical theory of species diversity. Journal of Biogeography, 28, 453-470.

Willig, M.R., Kaufman, D.M. \& Stevens, R.D. (2003) Latitudinal gradients of biodiversity: pattern, process, scale, and synthesis. Annual Review of Ecology, Evolution, and Systematics, 34, 273-309.
Zuur, A.F., Ieno, E.N., Walker, N.J., Saveliev, A.A. \& Smith, G.M. (2009) Mixed Effects Models and Extensions in Ecology with R, 1st edn. Springer Science + Business Media, New York.

Received 21 November 2011; accepted 15 May 2012

Handling Editor: Sedonia Sipes

\section{Supporting Information}

Additional supporting information may be found in the online version of this article:

Figure S1. Checkerboard-like grid.

Table S1. List of acacia species

Table S2. Results from ordinary least square regressions modelling the determinants of acacia species richness.

Appendix S1. Supplementary methods.

As a service to our authors and readers, this journal provides supporting information supplied by the authors. Such materials may be re-organized for online delivery, but are not copy-edited or typeset. Technical support issues arising from supporting information (other than missing files) should be addressed to the authors. 